Methods A total of 96 households treating water at home, by boiling $(\mathrm{n}=15)$, filtration $(\mathrm{n}=6)$ or sodium hypochlorite solution (Safewat ${ }^{\circledR}$ $\mathrm{n}=75$ ) in urban slums of Haridwar and Dehradun districts of Uttarakhand were studied. Respondents were administered a pre tested semi-structured interview schedule for identification, measurement and valuation of all the resources involved in these three methods. The mean and $95 \% \mathrm{CIs}$ of cost of treating ten litres of drinking water were estimated.

Results The cost of using Safewat, water filter and boiling was estimated to be INR 1.44[1] (1.29-1.50) INR 1.79 (1.31-2.27) INR 5.82 (5.24-6.40) per ten litres of water treated respectively. The cost of boiling was high because of the cost of fuel (69\%) despite a subsidy by the government on the gas. The use of filter required an initial capital investment for. purchase of filter (Approximately INR 500). Safewat solution accounted for $13 \%$ of the total cost of treatment by chlorination.

Conclusion Assuming similar effectiveness rates, Safewat use appears a more affordable alternative, with little initial investment. This makes a case for promotion, by the physicians, of water chlorination in place of the more costly option of boiling, which has been advocated for long.

\section{SP5-29 CARDIOVASCULAR RISK FACTORS AMONG SANTAL POPULATION IN BANGLADESH}

doi:10.1136/jech.2011.142976p.65

${ }^{1} \mathrm{~K}$ Fatema, ${ }^{*}{ }^{1} \mathrm{~N}$ Islam, 'L Ali. ${ }^{1}$ Bangladesh Institute of Health Sciences, Dhaka, Bangladesh; ${ }^{2}$ Dinajpur Medical College, Dinajpur, Bangladesh

Introduction In Bangladesh tribal race constitutes $<1 \%$ and among them Santals is the oldest and largest ethnic group. Data on risk factors of CVDs in Bangladesh, specially from tribal, are virtually nonexistent. The present study was undertaken to explore the anthropometric and clinical risk factors among the Santal in Bangladesh.

Methods A total of 316 Santal participants (135 male and 181 female, aged $\geq 20$ years) were screened through camps from the northwestern part of Bangladesh. Sociodemographic, anthropometric and clinical data were collected and OGTT preformed following WHO guidelines.

Results The age $(\mathrm{M} \pm \mathrm{SD}$ ) of the subjects was 39 ( \pm 11 ) years, BMI 18.7 \pm 2.8 ; WHR 0.85 \pm 0.17 . Using BMI for Asian 61.3\% found underweight of whom $35 \%, 12 \%$ and $14 \%$ were in chronic energy deficiency stage I, II and III respectively; for WHR females were in risk $(70 \%)$ which not corresponding with male (within range $94 \%$ ). Among males \& females alcohol habits ( $\geq 3$ serves/day) had $93 \%$ and $64 \%$; prevalence of hypertension were $15.6 \%$ and $7.2 \%$; dyslipidemia $49 \%$ and $29 \%$ respectively. Males had high (77\%) smoking habits. The prevalence of diabetes and prediabetes among the participants were $4.4 \%$ and $11.1 \%$. Hypertension showed significant association with age, chol, LDL and dyslipidemea with BMI, 2HBG and SBP on logistic regression analysis $(p<0.05)$.

Conclusion A substantial number of Santals are still suffering from underweight. All kind of RR are less among Santal comparing with the existing increased pattern of CVDs risk in Bangladesh, focussed attention need to reduce smoking and alcohol consumption.

\section{SP5-30 EVALUATING THE IMPLEMENTATION OF TRACHOMOA TREATMENT GUIDELINES IN AUSTRALIA}

doi:10.1136/jech.2011.142976p.66

M Kelaher, ${ }^{*}$ A Ferdinand, $\mathrm{H}$ Taylor. University of Melbourne, Melbourne, Australia

Introduction Trachoma control guidelines for the WHO recommend the SAFE strategy which includes surgery for trichiasis, antibiotic treatment, facial cleanliness and environmental improvement.
Australia is the only developed country where trachoma persists. In contrast to other countries, it has largely been assumed that lack of access to antibiotics and health services is not a major contributor to the persistence of trachoma in Australia. We assessed the relationship between reported treatment with azithromycin, levels of treatment required on WHO guidelines and the supply of azithromycin.

Methods Data on the supply of azithromycin to health services (2007/2008) was obtained from Medicare Australia. The reported treatment with azithromycin reported by individuals and trachoma prevalence was estimated based on data from the National Trachoma Surveillance and Reporting Unit (NTSRU) in 2008.

Results Reported treatment by Azithromycin was below levels suggested WHO guidelines. This disparity occurred despite the presence of sufficient available doses at health services.

Conclusion All aspects of the SAFE strategy are important in the eradication of trachoma. However, improving the supply and distribution of azithromycin is relatively easy to implement, fund and monitor. This study highlights the importance of continued focus on the delivery of azithromycin in the treatment of trachoma.

\section{SP5-31 FOOD AND NUTRITIONAL INSECURITY AMONG COLLECTORS OF RECYCLED MATERIAL IN SOUTHERN BRAZIL, 2010}

doi:10.1136/jech.2011.142976p.67

${ }^{1} \mathrm{~F}$ Auler, ${ }^{* 1} \mathrm{~A}$ Nakashima, ${ }^{1} \mathrm{C}$ Rosaneli, ${ }^{2} \mathrm{~A}$ de Moraes, ${ }^{1} \mathrm{~L}$ Ricardi, ${ }^{1} \mathrm{~T}$ Souza. ${ }^{1}$ Pontifical Catholic University of Paraná, Maringá, Paraná, Brazil; '2University of São Paulo, São Paulo, São Paulo, Brazil

The objective of this study was to estimate the prevalence of Food and Nutritional Insecurity (FNI) and its association with sociodemographic factors in a population under social vulnerability of a metropolitan region in the Southern Brazil. The outcome (FNI) was determined through the Brazilian Food Insecurity Scale and the independent variables analysed were gender, skin colour, age, marital status and scholarity. Categorical variables are presented in percentages and $\chi^{2}$ test (Yates' correction for $2 \times 2$ tables) analysed the existence of associations. The significance (p) was set at $5 \%$. The sample was formed by 123 collectors of recycled material members of six cooperatives. The FNI in this population was high (61\%), and according to the independent variables the prevalences were: adults $92 \%$, non-white $70.7 \%$, women $69.3 \%$, non-married $54.7 \%$ and illiterate $52 \%$. The statistical analysis only showed association with gender, women presented more prevalence of FNI than men, $69.3 \%$ and $30.7 \%$ respectively, $(p=0.002)$ The results showed high prevalence of FNI in the population investigated and the women have more probability to present food intake in insufficient quality and quantity. This way actions that aim the improvement of adequate food intake access without damaging the access to other essential necessities like food intake practices promoters health that respect the cultural diversity and that is, environmentally, culturally, economically and socially sustainable must be intensified once Brazil has public politics in this area but does not achieve the investigated population in the correct way.

\section{SP5-32 RISK PROFILE FOR TRANSMISSION OF MYCOBACTERIUM ULCERANS IN AKUAPEM SOUTH AND SUHUM KRABOA- COALTAR, GHANA}

doi:10.1136/jech.2011.142976p.68

${ }^{1} \mathrm{E}$ Kenu, ${ }^{*} \mathrm{R}$ Adanu, ${ }^{2} \mathrm{O}$ Razum, ${ }^{1} \mathrm{~F}$ Binka. ${ }^{1}$ University of Ghana, Accra, Ghana; ${ }^{2}$ University of Bielefield, Bielefield, Germany

Introduction Buruli ulcer (BU) disease is a chronic debilitating skin disease caused by Mycobacterium Ulcerans. The ulcer can be so 